\title{
Effects of Coatings with Pectin and Cinnamomum verum Hydrosol Included Pectin on Physical Characteristics and Shelf Life of Chicken Eggs Stored at $30^{\circ} \mathrm{C}$
}

\author{
Zohreh Didar*
}

Department of Food Science and Technology, Neyshabur Branch, Faculty of Science, Islamic Azad University, Neyshabur, Iran

\section{A B S T RAC T}

Background and Objectives: Increased environmental concerns about synthetic packaging have promoted developments of novel, environmentally-friendly edible films. In the present study, the quality parameters of chicken egg coated with pectin or pectin incorporated cinnamon hydrosol was assessed.

Materials and Methods: Egg chicken were coated with pectin and pectin prepared with cinnamon hydrosol and quality indicators (weight loss, yolk index, albumen $\mathrm{pH}$ and Haugh unit were assessed during storage at $30^{\circ} \mathrm{C}$. Microbiological analysis of Salmonella, Escherichia coli and Staphylococcus aureus and the total microbial count were carried out.

Results: Results showed that coating eggs with both pectin and cinnamon hydrosol included pectin caused lower weight loss during storage, compared to control eggs $(P<0.01)$. A Higher Haugh unit and yolk index were observed in coated eggs compared to control eggs. Scanning electron microscopy exhibited structural homogeneity of hydrosol included pectin coat. The microbiological analysis showed that the total plate count of all samples at Week 1 of storage was zero. In uncoated eggs, the total plate count reached to $3 \mathrm{CFU} \mathrm{ml}^{-1}$ at Week 6 of storage. The total plate count of two coated eggs was zero all over the storage time period. Three bacterial (Salmonella, E. coil and S. aureus) count included zero values from Week 1 to Week 6 of storage for all samples.

Conclusions: Coating of eggs with pectin especially pectin included cinnamon hydrosol resulted in better shelf life of eggs during 6 weeks of storage.

Keywords: Cinnamomum verum, Chicken egg, Coating, Hydrosol, Pectin

\section{Introduction}

Eggs have been a good source of food for humans since ancient times. They are one of the nature's perfect protein sources and include further highquality nutrients. Eggs are readily digested and can provide a significant portion of the nutrients required daily for growth and maintenance of the body tissues. These nutrients are used in food industries as well as homes (1). Hydrosol is a byproduct of the plant essential oil extraction. This product has unique properties, including low essential oils (less than $1 \mathrm{~g} \mathrm{l}^{-}$ ${ }^{1}$ ) and water solubility (2). Hydrosols include a good stability for more than one year. Studies have reported antimicrobial and antifungal properties of the plant hydrosols (3). Hydrosol extracted from Nepeta nepetella have shown strong antimicrobial effects against Klebsiella pneumoniae, Enterococcus faecalis, Staphylococcus aureus, Bacillus subtilis and Listeria monocytogenes (4). Antifungal (5) and antiviral (6) properties of various hydrosols have been reported as well. Antibiofilm activity of plant hydrosol also was reported (7).

Incorporation of plant extracts, especially essential oils, is an approach for transferring antimicrobial activity to packaging materials (8). Various formulation bases and food stuffs have been studied for this purpose, including alginate-based coating with oregano and rosemary essential oil for coating beef steaks (9), gelatin incorporated essential oils of Pistacia atlantica for coating fillets (10), curcumin loaded nanoemulsions/pectin for coating refrigerated chickens (11), and meat coating with gelatin and henna aqueous extracts (12). Eggs are susceptible to 
contamination by various microorganisms such as $S$. enteritidis and $S$. aureus (13). Generally, eggs prepared for consumption are washed; however, this method includes disadvantage such as huge water consumption and wastewater production. It is possible that contaminating microorganisms enter interior parts of the egg during washing processes (14). Other methods for decontamination of eggs have been suggested, including infrared radiation (15); however, radiation methods may not be accepted by the consumers. The present study is focused on investigating effects of coating with pectin or cinnamon hydrosol included pectin on the quality and microbial analysis of chicken eggs stored at $30^{\circ} \mathrm{C}$.

\section{Materials and Methods}

High-ester pectin, ethanol, nutrient agar (NA), MacConkey agar, brilliant green bile broth, Salmonella-Shigella (SS) agar and Tryptic Soy Agar (TSA) were purchased from Merck, Germany.

Hydrosol extractio: Dried cinnamon (Cinnamomum verum) was purchased from a local market in Neyshabur, Iran. Hydrosol was extracted using the following method (16). Briefly, $100 \mathrm{~g}$ of the ground cinnamon were transferred into a flask and mixed with sterile water with a ratio of cinnamon:water as $1: 10 \mathrm{w} \mathrm{v}^{-1}$. The Clevenger apparatus was setup and hydrodistillation was carried out for $2 \mathrm{~h}$. After hydrodistillation, essential oil was removed using separator funnel. Hydrosols were stored at $4{ }^{\circ} \mathrm{C}$ in sterile bottles until use.

Gas chromatography-mass spectroscopy (GC-MS) analysis of cinnamon hydrosol: The GC-MS of cinnamon hydrosol was carried out using Agilent Technologies 7890A GC System equipped with 5975CVLMSD Mass Spectrometer and Series 7683B Injector. The column characteristics included Agilent (9091) HP-5 Column with 320- $\mu \mathrm{m}$ diameter, 30-m length and film thickness of $0.25 \mu \mathrm{m}$.

Selection of eggs: In general, 200 brown-shell eggs were purchased from a local producer. All the selected eggs were free of cracks, dirt and other defects.

Pectin coat preparation and egg coating: High-ester pectin powder $\left(6 \% \mathrm{w} \mathrm{v}^{-1}\right)$ was dissolved in hydrosol extracted from cinnamon at room temperature and stirred at $500 \mathrm{rpm}$ for $20 \mathrm{~min}$ until being fully solubilized (11). Then, eggs were immersed in the prepared pectin solution for $1 \mathrm{~min}$.
Scanning electron microscope (SEM): For assessing structures of pectin coats, a SEM (Phenom ProX, Thermo Fisher Scientific, USA) with a magnification power of 500-10000 was used.

Storage of eggs: After coating, all eggs were dried at ambient temperature for $24 \mathrm{~h}$. Uncoated eggs were used as controls. Eggs were stored at $30{ }^{\circ} \mathrm{C}$ for six weeks. Quality parameters of Haugh unit, yolk index, albumen and yolk $\mathrm{pH}$, weight loss and microbial analysis (including Salmonella spp. E. coli and S. aureus detection) were measured $24 \mathrm{~h}$ post coating (Week 0) and at specific intervals for six weeks of storage.

Weight loss calculation: Weight loss in eggs were calculated during storage using the fallowing Formula.

Weight loss $(\%)=$ $\frac{\text { Initial whole egg }(g) \text { at day } 0-\text { whole egg weight }(\mathrm{g}) \text { after storage time }}{\text { Initial whole egg weight }(g) \text { at day } 0} \times 100$

The weight of eggs was recorded using analytical balance (AND FA 2104, USA). Five measurements were carried out for each treatment per week.

Calculation of Haugh unit and yolk index: Eggs were broken on a flat surface and height of thick albumen and yolk and the yolk width were calculated using Guanglu 25-0 Model 701-211 Digital Micrometer (Guanglu, China). Each parameter was calculated for three different points of yolk and albumen and the average mean was calculated. The Haugh unit was calculated using the fallowing equation.

Haugh unit $=100 \log (\mathrm{H}-1.7 \mathrm{~W} 0.37+7.57)$

Where, $\mathrm{H}$ was the albumen height $(\mathrm{mm})$ and $\mathrm{W}$ was the weight (g) of egg (17). The yolk index was calculated by dividing yolk height to yolk width.

Assessment of yolk and albumen pH: First, albumen and yolk were separated and albumen was thoroughly mixed. Then, albumen and yolk $\mathrm{pH}$ were measured separately using digital $\mathrm{pH}$ meter (Metrohm, Germany) at $25^{\circ} \mathrm{C}$.

Microbial analysis: The total plate count (TPC), Salmonella spp., E .coli and S. aureus from contents of the eggs was analyzed every two weeks during the experiment. First, eggshells were sterilized using $70 \%$ ethanol and contents of the eggs were transferred into a sterilized beaker and mixed using sterile glass rod. The NA was used for TPC at $37{ }^{\circ} \mathrm{C}$ for $48 \mathrm{~h}$. For 
enumeration of $E$.coli, MacConkey agar and BGB broth were used. The SS agar was used for the identification and enumeration of Salmonella spp. Identification of $S$. aureus was carried out using TSA. All microbiological assays were carried out in duplicate for each treatment.

Statistical analysis: All experiments were carried out in triplicate. Statistical analysis was carried out using completely randomized design, analysis of variance (ANOVA) and STATISTICA Software v.13.

\section{Results}

Chemical composition of cinnamon hydrosol was analyzed using GC-MASS analysis (Table 1).

Morphological assessments of pectin coats (with or without cinnamon hydrosol) were carried out using
SEM at 500-10,000 magnifications. Figure 1 exhibit the electron micrographs of pectin coats with or without cinnamon hydrosol. It is clear that pectin coating with cinnamon hydrosol included a better homogeneous texture and further structural continuity in all magnification ranges (500-10000).

Effects of coating on egg quality parameters: In this study, a variety of egg quality parameters, including weight loss, yolk index, albumen $\mathrm{pH}$ and Haugh unit were assessed during storage at $30^{\circ} \mathrm{C}$ (Table 2).

Microbiological analysis of the samples, including uncoated, pectin coated and pectin with cinnamon hydrosol samples, was carried out based on the enumeration of salmonella, E. coli, S. aureus and TPC of eggs stored at $30^{\circ} \mathrm{C}$ for $0-6$ weeks.

Table 1. Chemical composition of cinnamon (Cinnamomum verum) hydrosol

\begin{tabular}{llll}
\hline No. & Retention time (min) & Component & Yield \% \\
\hline 1 & 20.398 & Cinnamic acid, methyl ester & 6.35 \\
2 & 27.684 & Methyl palmitate & 15.86 \\
3 & 27.701 & Hexadecanoic acid methyl ester & 4.5 \\
4 & 28.657 & Corymbolone & 3.77 \\
5 & 28.814 & 3-Cyclohexen-1-carboxaldehyde, 3,4-dimethyl & 10.71 \\
6 & 28.867 & Vulgarol & 3.47 \\
7 & 28.902 & Alloaromadendrene oxide & 1.51 \\
8 & 37.843 & 9-Octadecenoic acid & 5.54 \\
9 & 37.895 & 6-Formyl-3- methyl- 2- oxo- 4- hexenoic acid. & 4.5 \\
10 & 39.388 & 1-Eicosene & 3.12 \\
11 & 39.440 & Cyclopropaneoctanal & 0.88 \\
12 & 39.644 & Emersol & 8.8 \\
13 & 39.667 & 1-Nonadecene & 1.57 \\
\hline
\end{tabular}

Table 2. Characterization of eggs with or without coating

\begin{tabular}{lllll}
\hline & Week & Control egg & Egg coated with pectin & Egg coated with pectin with cinnamon hydrosol \\
\hline Weight loss (\%) & 2 & $2.3 \pm 0.07$ & $1.32 \pm 0.2$ & $0.8 \pm 0.06$ \\
& 4 & $5.3 \pm 0.19$ & $3.7 \pm 0.6$ & $2.6 \pm 0.1$ \\
& 6 & $7.2 \pm 0.15$ & $4.29 \pm 0.8$ & $3.5 \pm 0.3$ \\
Yolk index & 0 & $0.5 \pm 0.02$ & $0.5 \pm 0.02$ & $0.5 \pm 0.02$ \\
& 2 & $0.32 \pm 0.01$ & $0.41 \pm 0.02$ & $0.46 \pm 0.03$ \\
& 4 & $0.25 \pm 0.01$ & $0.32 \pm 0.01$ & $0.4 \pm 0.04$ \\
Albumen pH & 6 & $0.17 \pm 0.01$ & $0.28 \pm 0.03$ & $0.32 \pm 0.05$ \\
& 0 & $7.8 \pm 0.2$ & $7.8 \pm 0.2$ & $7.8 \pm 0.2$ \\
& 2 & $8.1 \pm 0.1$ & $8 \pm 0.1$ & $8 \pm 0.1$ \\
Haugh unit & 4 & $8.7 \pm 0.1$ & $8.2 \pm 0.1$ & $8.1 \pm 0.1$ \\
& 6 & $9.5 \pm 0.2$ & $8.8 \pm 0.1$ & $8.2 \pm 0.2$ \\
& 0 & $86.75 \pm 2.1$ & $86.75 \pm 2.1$ & $86.75 \pm 2.1$ \\
& 2 & $79.23 \pm 2.01$ & $82.1 \pm 1.7$ & $84.1 \pm 1.5$ \\
& 4 & $61.13 \pm 2.5$ & $78.3 \pm 1.9$ & $79.6 \pm 2.01$ \\
\hline
\end{tabular}


$\mathbf{a}$
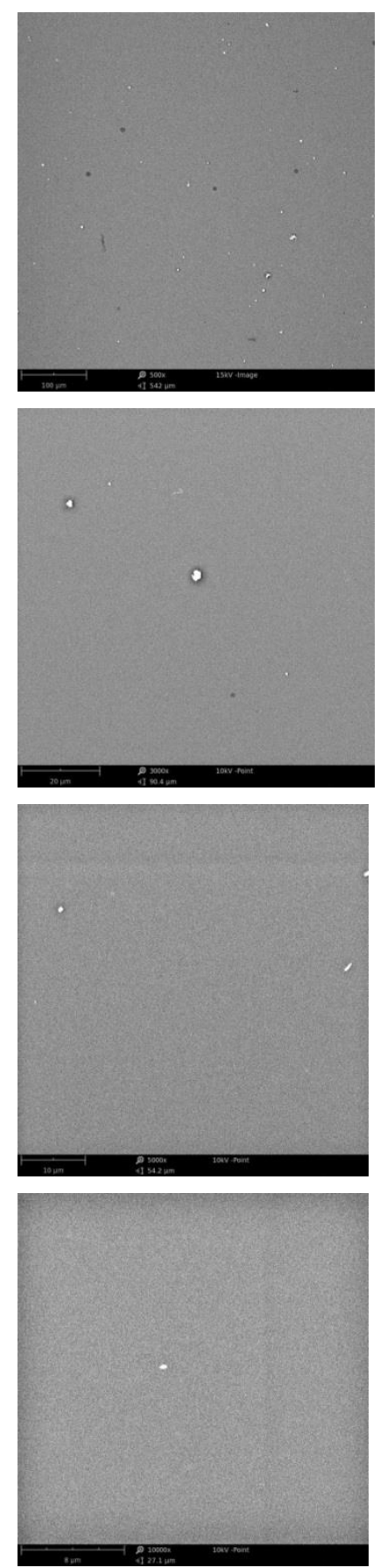

Figure 1. The SEM micrographs of pectin films without (a) or with (b) cinnamon hydrosol

\section{Discussion}

As shown at Table 1, various components from various chemical groups, including hydrocarbons, aldehydes and acids, were detected in cinnamon hydrosols. An indicator component in cinnamon hydrosol was cinnamic acid methyl ester with a yield of $6.35 \%$. Hydrosol composition of plants includes diverse qualities (3). Inouye et al. (2008) categorized plant hydrosols into six classes based on the plant functional groups. These classes included aldehyde, alcohol, phenol, ketone, ester and phenol methyl ether groups (18). De Matos et al. (2015) reported that the major composition of plant hydrosols included triketones, tasmanones, flavesones and agglomerones (19). Hydrosol chemical composition can vary depending on several factors such as plant parts, climatic conditions, extraction method, geographical origins and genetic structures as well as methods used for drying plants (20). Shen et al. (2017) detected 44 various components in extracted hydrosols of Areca catechu L. and Cocos nucifera $\mathrm{L}$. These components included hydrocarbons, alcohols, ketones, aldehydes, esters, acids and other compounds (21). In the current study, SEM micrographs of pectin coats (alone or with cinnamon hydrosols) showed good uniformity in coat structures, especially in coats containg cinnamon hydrosols (Fig. 1). The water solubility nature of cinnamon hydrosols replaces pectin structure; in contrast to essential oils in edible film formulas that cause heterogeneity in structure of the film due to the insolubility of plant essential oils in water (22). This homogeneity in the structure of pectin coats incorporated with cinnamon hydrosols could be the key property that resulted in a lower water loss, as well as changes in yolk indices and $\mathrm{pH}$ of albumen during storage. Because of this structure, escape of gases and moistures in eggs treated with pectincinnamon hydrosol was delayed and a longer shelf life of these samples was observed.

In this study, assessment results for the quality parameters of egg samples during storage at $30^{\circ} \mathrm{C}$ for six weeks showed significant changes $(\mathrm{P}<0.01)$. Weight loss in coated or uncoated eggs was seen. The highest weight loss value belong to uncoated eggs, especially at the end of storage $(7.2 \pm 0.15 \%)$. Effects of pectin coating on decrease of weight loss in eggs (with or without cinnamon hydrosols) could be attributed to the structure of this coats that covers pores on the shell surface and prevents evaporation of water and $\mathrm{CO}_{2}$ from inside of the eggs. The SEM supported this hypothesis. Relative standards by FAO (Food and Agriculture Organization, 2003) permit weight losses in a range of $2-3 \%$ for eggs (23). The major reasons of weight loss in eggs include 1) water evaporation during storage, and 2) loss of $\mathrm{CO}_{2}$ through the shell (24). Weight loss is an important indicator of egg quality. Haugh unit is an indicator for 
the assessment of albumen and yolk quality in eggs. A higher Haugh unit value indicates a better quality of eggs. Results from assessment of this parameter in all eggs showed that eggs with pectin coats (with or without cinnamon hydrosols) included a better quality in term of Haugh unit (Table 2). In the present study, a significant difference was seen between the coated and uncoated eggs $(P<0.01)$. At Week 1 of storage, the Haugh unit of all eggs included $86.75 \pm 2.1$. However, a progressive decrease was observed in this parameter during the storage. The Haugh unit value decreased gradually in all samples with the rate of decreased Haugh unit was slower in coated eggs (Table 2). The Haugh unit decrease progressed as the storage time increased. At the end of storage, the Haugh unit values of uncoated, pectin coated and pectin-cinnamon hydrosol coated eggs reached to $42.03 \pm 1.8,59.51 \pm 1.2$ and $62.21 \pm 1.6$, respectively.

During storage of eggs, interactions between ovomucin and lysozyme, $\alpha$ and $\beta$ ovomucins disulfide bonds of ovomucin and carbohydrate moieties of ovomucin cause thinning of the albumen and changing of the Haugh unit (25). Similar results have been reported by previous studies (26). Based on the Haugh unit, eggs are categorizes into four major classes of AA (above 72), A (72-60), B (59-31) and $\mathrm{C}$ (below 30) (27). In the current study, quality of the egg samples could be classified into AA (coated eggs) and B (uncoated eggs) after six weeks of storage. Other quality indices of eggs changed during the storage, including yolk index and albumen $\mathrm{pH}$ (Table 2). In all egg samples, yolk index decreased during the storage by different rates. Weakened vitelline membranes, decreased total solids and liquefied yolks are parameters that resulted in decreased yolk indices (an important indicator of egg freshness) during storage. This occurred due to the osmotic diffusion of water from the albumen (24). In this study, yolk quality indices of uncoated and coated eggs were assessed and found significant differences between the samples $(P<0.01)$. The storage time directly affected yolk indices. Longer storage times resulted in further yolk quality decreases. Quality loss rate of the yolk index in uncoated eggs was faster than that in coated eggs. Results could be attributed to the structure of pectin films and homogeneity of this structure that covers pores on the eggshell and causes lower water and $\mathrm{CO}_{2}$ losses from the shell, inhibiting albumen liquefaction and water uptake by the yolk; as shown by other by other researchers. Torrico et al. (2011) showed a direct relationship between the Haugh unit, weight loss and yolk index (28).

In fact, $\mathrm{pH}$ of albumen is another major indicator of the egg quality. Fresh eggs contain nearly $1.44-2.05$ mg $\mathrm{CO}_{2} \mathrm{~g}^{-1}$ of albumen and have an albumen $\mathrm{pH}$ of 7.6-8.7 (29). At Day 1 of this study, all eggs included a $\mathrm{pH}$ of $7.8 \pm 0.2$. However, $\mathrm{pH}$ of all samples increased and significant differences were seen between the samples in term of albumen $\mathrm{pH}(P<$ 0.01). A direct correlation is described between the albumen $\mathrm{pH}$ and $\mathrm{CO}_{2}$ release from the eggshell. As previously highlighted, pectin coats cover the shell pores and hence inhibit escape of $\mathrm{CO}_{2}$ from inside of the egg. The $\mathrm{pH}$ changing of samples during storage is affected by several factors such as coating treatment and storage time. Eggs coated with pectin and pectin-cinnamon hydrosol showed approximately a relatively similar pattern but uncoated eggs showed a different $\mathrm{pH}$ changing. Results from this study were similar to results by other studies. Jirangrat et al. (2010) demonstrated that albumen $\mathrm{pH}$ of uncoated eggs significantly increased from 8.71 to 9.42 $(P<0.05)$, while albumen $\mathrm{pH}$ of coated eggs with mineral oils decreased from 8.71 to 8.64 after five weeks of storage at ambient temperature (26). During storage, carbon dioxide escapes through the eggshell pores and causes thinning of the first albumen, resulting in increased albumen $\mathrm{pH}$ to 9.6-9.7 (30). Another reason for the decrease of albumen $\mathrm{pH}$ is progressive breakdown of the constituents in egg white and/or changes in bicarbonate buffer system (24). During six weeks of storage, the albumen $\mathrm{pH}$ magnitude mildly increased in all uncoated and coated eggs, compared to initial values $(P<0.01)$. Increases in $\mathrm{pH}$ were significantly higher in uncoated eggs (from 7.8 to 9.5 ) than those in coated eggs. The TPC of all samples was zero at Week 1 of storage. In

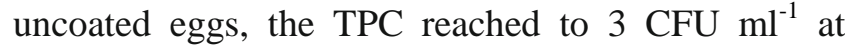
Week 6 of storage. The TPC of two coated eggs was zero in entire storage duration. Three bacterial count (Salmonella spp, E. coli and S. aureus) were zero from Weeks 1 to 6 of storage in all samples. Suresh et al. (2015) reported no Salmonella, E. coli, mold or yeast growth in eggs coated with chitosan (31). Egg products are safe if they include less than $5.0 \times 10^{4}$ CFU g ${ }^{-1}$ of TPC and lack of Salmonella spp (32). 


\section{Acknowledgement}

Author is gratefully acknowledge the generous supports from the Islamic Azad University, Neyshabur Branch

\section{Financial disclosure}

The author does not have any potential conflict of interest to declare. This study received no specific grant from any funding agency in public, commercial or not-for-profit sector.

\section{References}

1. Belitz HD, Grosch W. Food Chemistry. Springer publication. 2010. 513-515.

2. Labadie C, Cerutti C, Carlin F. Fate and control of pathogenic and spoilage micro-organisms in orange blossom (Citrus aurantium), and rose flower (Rosa centifolia) hydrosols. Journal of Applied Microbiology. 2016; 121: 1568-1579.

3. D'Amato S, Serio A, Chaves Lopez C, Paparella A. Hydrosols: Biological activity and potential as antimicrobials for food Applications. Food Control. 2018; 86: 126-137.

4. Bellahsene C, Bendahou M, Khadir A, Zenati F, Benbelaïd F, Aissaoui N, Muselli A, Costa J. Antimicrobial activity and chemical composition of essential oil and hydrosol extract of Nepeta nepetella subsp. amethystina (Poir.) Briq. from Algeria. Journal of Applied Pharmaceutical Science. 2015; 5(9): 21-25.

5. Belabbes R, El Amine Di M, Djabou N, Ilias F, Tabti B, Costa J, Muselli A. Chemical variability, antioxidant and antifungal activities of essential oils and hydrosol extract of Calendula arvensis L. from western Algeria. Chemistry \& Biodiversity.2017; 14: doi: 10.1002/cbdv.201600482.

6. Kaewprom K, Chen Y-H, Lin CF, Ming-Tang Chiou MT, Chao-Nan Lin C-N. Antiviral activity of Thymus vulgaris and Nepeta cataria hydrosols against porcine reproductive and respiratory syndrome virus. Thai Journal of Veterinary Medicine. 2017; 47(1): 25-33.

7. Karampoula F, Giaouris E, Deschamps J, Doulgeraki A, Nychas G-J, Dubois-Brissonnet F. Hydrosol of Thymbra capitata Is a Highly Efficient Biocide against Salmonella enterica Serovar Typhimurium Biofilms. Applied and Environmental Microbiology. 2016; 72(17): 5309-5319.

8. Radi, M., Firouzi, E., Akhavan, H., and Sedigheh Amiri, S. Effect of Gelatin-Based Edible Coatings Incorporated with Aloe vera and Black and Green Tea Extracts on the Shelf Life of Fresh-Cut Oranges. Journal of Food Quality. 2017; https://doi.org/10.1155/2017/9764650.

9. Vital A C P, Ana Guerrero A, Monteschio J O, Velandia Valero M, Carvalho C B, Filho B A A,
Grasiele Madrona S, Prado IN. Effect of Edible and Active Coating (with Rosemary and Oregano Essential Oils) on Beef Characteristics and Consumer Acceptability PLOS. 2016; Available at: https://doi.org/10.1371/journal.pone.0160535.

10. Ranjbar M, Azizi MH. Microbial, Chemical, and Sensorial Properties of Chicken Fillets Coated by Gelatin-Carboxymethyl Cellulose Film Containing Essential Oil of Bene (Pistacia atlantica). Journal of food quality and hazards control. 2017; 4: 14-19.

11. Abdou, E.S., Galhoum, G.F., Mohamed, E.N. Curcumin loaded nanoemulsions/pectin coatings for refrigerated chicken Fillets. Food Hydrocolloids. 2018; 83 : 445453

12. Jridi M, Mora L, Souissi N, Aristoy M C, Nasri M, Fidel Toldra F. Effects of active gelatin coated with henna (L. inermis) extract on beef meat quality during chilled storage. Food Control. 2018; 84: 238-245.

13. Ekhtelat M, Rezvani S J, Safarloo A. 2012. Investigation of contamination to Salmonella and Staphylococcus aureus in native and industrial hen's eggs in Qhom areas. Journal of Veterinary Laboratory Research. 2012; 4: 309-314.

14. Hakimi Alni R, Sharifi A, Baraty S. Investigation the effect of washing on penetration of Salmonella in yolk and albumen of egg at $4^{\circ} \mathrm{C}$. 2012; 2th National Conference on Analytical Science of Veterinary. Semnan University.

15. Alkaya G B, Erdogdu F, Kadir Halkman A. Surface decontamination of whole-shell eggs using far-infrared radiation. Food and Bioproducts Processing. 2016; 98 : 275-282

16. Sagdic O. Sensitivity of four pathogenic bacteria to Turkish thyme and oregano hydrosols. LWT - Food Science and Technology. 2003; 36(5): 467-473.

17. Haugh R R. The Haugh unit for measuring egg quality. The U.S. Egg and Poultry Magazine. 1937; 43: 552 555 .

18. Inouye $\mathrm{S}$, Takahashi M, Abe S. A comparative study on the composition of forty four hydrosols and their essential oils. International Journal of Essential Oil Therapeutics. 2008; 2: 89-104.

19. De Matos I L, Machado S M F, de Souza A R, Costa E V, Nepel A, Barison A, et al. Constituents of essential oil and hydrolate of leaves of Campomanesia viatoris LANDRUM. Quimica Nova, 2015; 10: 1289-1292.

20. Sellami I H, Wannes W A, Bettaieb I, Berrima S, Chahed T, Marzouk B, et al. Qualitative and quantitative changes in the essential oil of Laurus nobilis L. leaves as affected by different drying methods. Food Chemistry. 2011; 126(2), 691-697.

21. Shen X, Chen W, Zheng Y, Lei X, Tang M, Wang H, Song F. Chemical composition, antibacterial and antioxidant activities of hydrosols from different parts of Areca catechu L. and Cocos nucifera L. Industrial Crops and Products. 2017; 96: 110-119. 
22. Bonilla J, Poloni T, Lourenco RV, Sobral P J A. Antioxidant potential of eugenol and ginger essential oils with gelatin/Chitosan films. Food Bioscience. $2018 ; 107-114$

23. Food and Agriculture Organization of the United Nations. Egg marketing-A guide for the production and sale of eggs. FAO Agricultural Services Bulletin 2003; 150. Rome, Italy: FAO Publications.

24. Obanu ZA, Mpieri AA. Efficiency of dietary vegetable oils in preserving the quality of shell eggs under ambient tropical conditions. Journal of the Science of Food and Agriculture. 1984; 35: 1311-1317.

25. Li- Chan $\mathrm{E}$ and Nakais. Biochemical basis for the properties of egg white. CRC Avian and Poultry Biology Reviews. 1989; 2(1): 21- 58.

26. Jirangrat W, Torrico DD, No J, No HK and Printawiwatkul W. Effects of mineral oil coating on internal quality of chicken eggs under refrigerated storage. International Journal of Food Science Technology. 2010; 45: 490-495.

27. Lee SH, No HK, Jeong YH. Effect of chitosan coating on quality of egg during storage. Journal of the Korean Society of Food Science and Nutrition. 1996; 25: 288 293.
28. Torrico DD, No HK, Prinyawiwatkul W, Janes ME, Herrer JA and Osorio LF. Mineral oil-Chitosan emulsion coatings affect quality and shelf-life of coated eggs during refrigerated and room temperature storage. Journal of Food Science. 2011; 6: 262-280.

29. Waimaleongora-Ek P, Garcia K, No HK, Prinyawiwatkul W and Ingram D. Selected quality and shelf-life of eggs coated with mineral oil with different viscosities. Journal of Food Science. 2009; 74: 423429.

30. Li- Chan E and Nakai S. Biochemical basis for the properties of egg white. CRC Critical Avian and Poultry Biology Reviews. 1989; 2(1): 21-58.

31. Suresh P V, Rathina Raj K, Nidheesh T, Kumar Pal G, Sakhare P Z. Application of chitosan for improvement of quality and shelf life of table eggs under tropical room conditions. Journal of Food Science and Technology. 2015; 52(10):6345-6354.

32. Ricke SC, Birkhold SG and Gast RK. Eggs and egg products. In: Downer, P.F. and Ito, K. eds. Compendium of methods for the microbiological examination of foods. Washington, D.C: 2001; American Public Health Association. 